\title{
A novel frameshift PKD1 mutation in a Chinese patient with autosomal dominant polycystic kidney disease and azoospermia: A case report
}

\author{
JIALIN MENG, YUCHEN XU, XUFENG SHEN and CHAOZHAO LIANG \\ Department of Urology, The First Affiliated Hospital of Anhui Medical University and Institute of Urology, \\ Anhui Medical University, Hefei, Anhui 230022, P.R. China
}

Received June 3, 2018; Accepted October 3, 2018

DOI: $10.3892 /$ etm.2018.6946

\begin{abstract}
Autosomal dominant polycystic kidney disease (ADPKD) is primarily caused by mutations in polycystin 1 , transient receptor potential channel interacting (PKD1) and PKD2, and characterized by numerous cysts in various organs, primarily the kidneys and liver. The present case report is on a 33-year-old Chinese male patient who suffered from abdominal pain and hypertension, and presented with long-term infertility. Laboratory tests indicated that the patient had a normal renal function, while abdominal computed tomography demonstrated that the patient had enlarged kidneys with a volume of $1,127.21 \mathrm{~cm}^{3}$. In a semen analysis, no sperm was detected, while a subsequent testicular biopsy analysis demonstrated numerous mature sperms with progressive motility which suggests that the cysts of the epididymis and the dilated seminal vesicles may have obstructed the ejaculation of semen. Genetic testing identified that a novel missense mutation (c.9053delT) that was responsible for the disease. ADPKD has various disease severities, which depend on whether there is a PKD1 or PKD2 mutation and whether the mutation impairs the function of the polycystin protein. Therefore, genetic testing is important for the clinical diagnosis and prognosis of ADPKD patients, as well as prenatal diagnosis.
\end{abstract}

\section{Introduction}

Autosomal dominant polycystic kidney disease (ADPKD) is the most frequently inherited kidney disease; its incidence has been reported to be $1 / 400$ to $1 / 2,500$ worldwide and

Correspondence to: Professor Chaozhao Liang, Department of Urology, The First Affiliated Hospital of Anhui Medical University and Institute of Urology, Anhui Medical University, 218 Jixi Road, Shushan, Hefei, Anhui 230022, P.R. China

E-mail: liang_chaozhao@ahmu.edu.cn

Key words: polycystic kidney disease, total kidney volume, polycystin 1, azoospermia, transient receptor potential channel interacting, frameshift mutation
1.5 million individuals are affected in China (1-4). A common cause of ADPKD is a mutation in polycystin (PC)-1, a transient receptor potential channel which interacts with (PKD1) and/or PKD2, and accounts for 85 and $15 \%$ of all detectable cases of ADPKD, respectively. Approximately $10 \%$ of patients with ADPKD have no detectable PKD1 or PKD2 mutation, which may be attributed to the current lack of effective testing methods or to similar kidney cysts caused by other gene mutations $(5,6)$. ADPKD is characterized by numerous enlarged cysts in the bilateral kidneys and liver, in addition to specific rare manifestations in other organs, including the pancreas, cerebral vasculature, aortic arch and seminal vesicles (7-10). In the case of the present study, a novel frameshift PKD1 mutation was identified in ADPKD, which additionally caused epididymal cysts and azoospermia.

\section{Case report}

In September 2017, a 33-year-old male patient presented at the outpatient department of the First Affiliated Hospital of Anhui Medical University (Hefei, China) and sought medical advice due to the complaint of abdominal pain and azoospermia. He was first diagnosed with ADPKD in 2014 by magnetic resonance imaging, which identified numerous cysts in the kidneys and liver, based on the standard of diagnosis established by Pei et al (11). In 2016, the patient was diagnosed with azoospermia by semen analysis following long-term infertility and he additionally developed hypertension with a peak blood pressure of $150 / 100 \mathrm{mmHg}$, which was controlled with Valsartan tablets.

The patient had a height of $180 \mathrm{~cm}$, weight of $75 \mathrm{~kg}$ and body mass index of $23.1 \mathrm{~kg} / \mathrm{m}^{2}$. Mild pain with a pain score of 1 was determined using a visual analog scale, as previously described (12). The latest laboratory investigations demonstrated a normal serum creatinine concentration $(81.7 \mu \mathrm{mol} / 1$; normal range: $61.9-114.9 \mu \mathrm{mol} / \mathrm{l})$, blood urea nitrogen concentration $(6.31 \mathrm{mmol} / 1$; normal range: 2.5-7.1 $\mu \mathrm{mol} / \mathrm{l}$ ) and estimated glomerular filtration rate (eGFR; $106.78 \mathrm{ml} / \mathrm{min} / 1.73 \mathrm{~m}^{2}$; normal range: $90-120 \mathrm{ml} / \mathrm{min} / 1.73 \mathrm{~m}^{2}$ ), and an increased uric acid concentration $(506 \mu \mathrm{mol} / \mathrm{l}$; normal range: $214-494 \mu \mathrm{mol} / \mathrm{l})$. By analyzing the patient's previous laboratory results, it was identified that the eGFR was within 

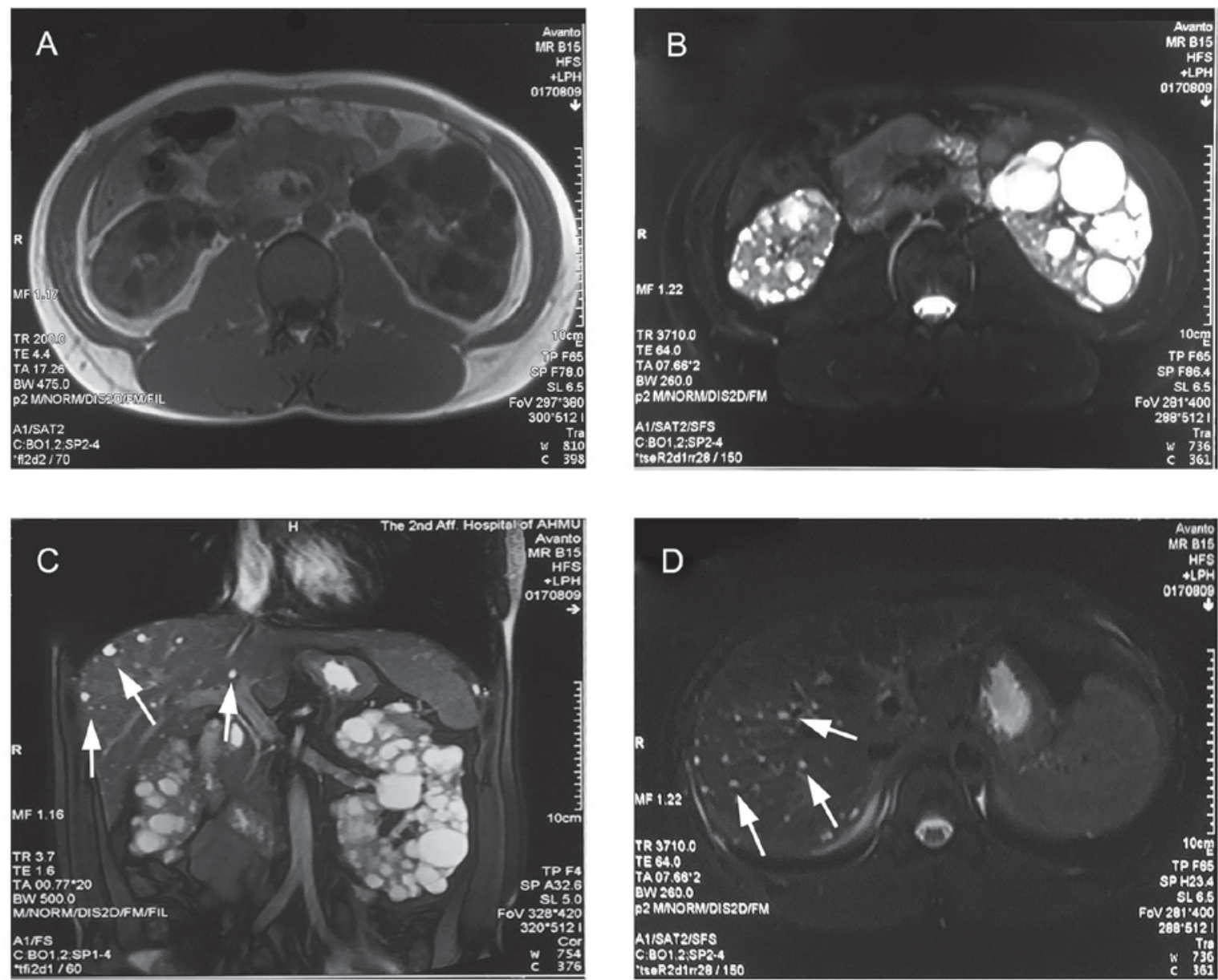

Figure 1. Abdominal CT imaging revealed enlarged kidneys with fluid-filled cysts. (A) CT scan revealed bilateral renal enlargement (transverse plane). (B) CT contrast enhancement of bilateral renal enlargement (transverse plane). (C) CT scan of the isolated liver cysts (coronal plane). (D) CT scan of the isolated liver cysts (transverse plane). The white arrows indicate the isolated liver cysts. CT, computed tomography.

the normal range from July 2015 to March 2018, without any abnormal result in December $2016\left(86.91 \mathrm{ml} / \mathrm{min} / 1.73 \mathrm{~m}^{2}\right)$. The most recent abdominal computed tomography performed on the 14th of February 2016, demonstrated that the kidneys were significantly enlarged with numerous cysts of varying sizes with a total kidney volume of $1,127.21 \mathrm{~cm}^{3}$, while there were some isolated small cysts present in the liver (Fig. 1). In the semen analysis in July and August 2017, no sperm was detected, along with a low volume of ejaculate $(2$ and $2.3 \mathrm{ml}$, respectively). In the subsequent ultrasound examination, cysts were identified in the bilateral epididymis, with a size of $6 \mathrm{~mm}$ on the left and $4 \mathrm{~mm}$ on the right, in addition to dilated seminal vesicles. Of note, the subsequent testicular biopsy identified numerous mature sperms with progressive motility.

In order to make a definitive diagnosis of ADPKD, the patient was subjected to genetic sequencing analysis of the PKD1 and PKD2 genes. No mutation in the PKD2 gene was identified, whereas the coding region of PKD1 in the patient exhibited a c.9053delT frameshift mutation (p.Phe3018Serfs"56; Fig. 2), which has not been previously reported, to the best of our knowledge, in the 1,000 Genomes project, the Exome Aggregation Consortium or the PKD mutation database (13-15). Prediction regarding the effects of this mutation with Mutation Taster (www.mutationtaster.org) and PolyPhen-2 (genetics.bwh.harvard.edu/pph2) software indicated that the protein variant is 'disease-causing' and 'probably damaging', respectively, which is in line with the situation of the present case. Sanger sequencing of the mother of the patient revealed no mutations in PKD1 or PKD2; renal function was in the normal range and there were no kidney cysts observed. The father of the patient died in a motor vehicle collision in 2005 at the age of 50 years, and therefore, it was not possible to perform Sanger sequencing, however he had normal kidney function and no family history of kidney disease.

\section{Discussion}

ADPKD is a prevalent inherited kidney disease, commonly caused by a mutation of PKD1 and/or PKD2 in the majority of cases. The mutation in the remaining $10 \%$ of patients is undetectable, which may be attributed to the current lack of effective testing methods, or to similar kidney cysts caused by other gene mutations $(5,6)$; the glucosidase II $\alpha$ subunit gene, which serves a role in protein folding and quality control, may be another potential causal gene that induces ADPKD phenotypes (16). Due to the advantages of low cost and high-throughput, the technology of next-generation sequencing is widely applied in the diagnosis and study of hereditary disease, including ADPKD (17-20). However, its short-read sequencing approaches 

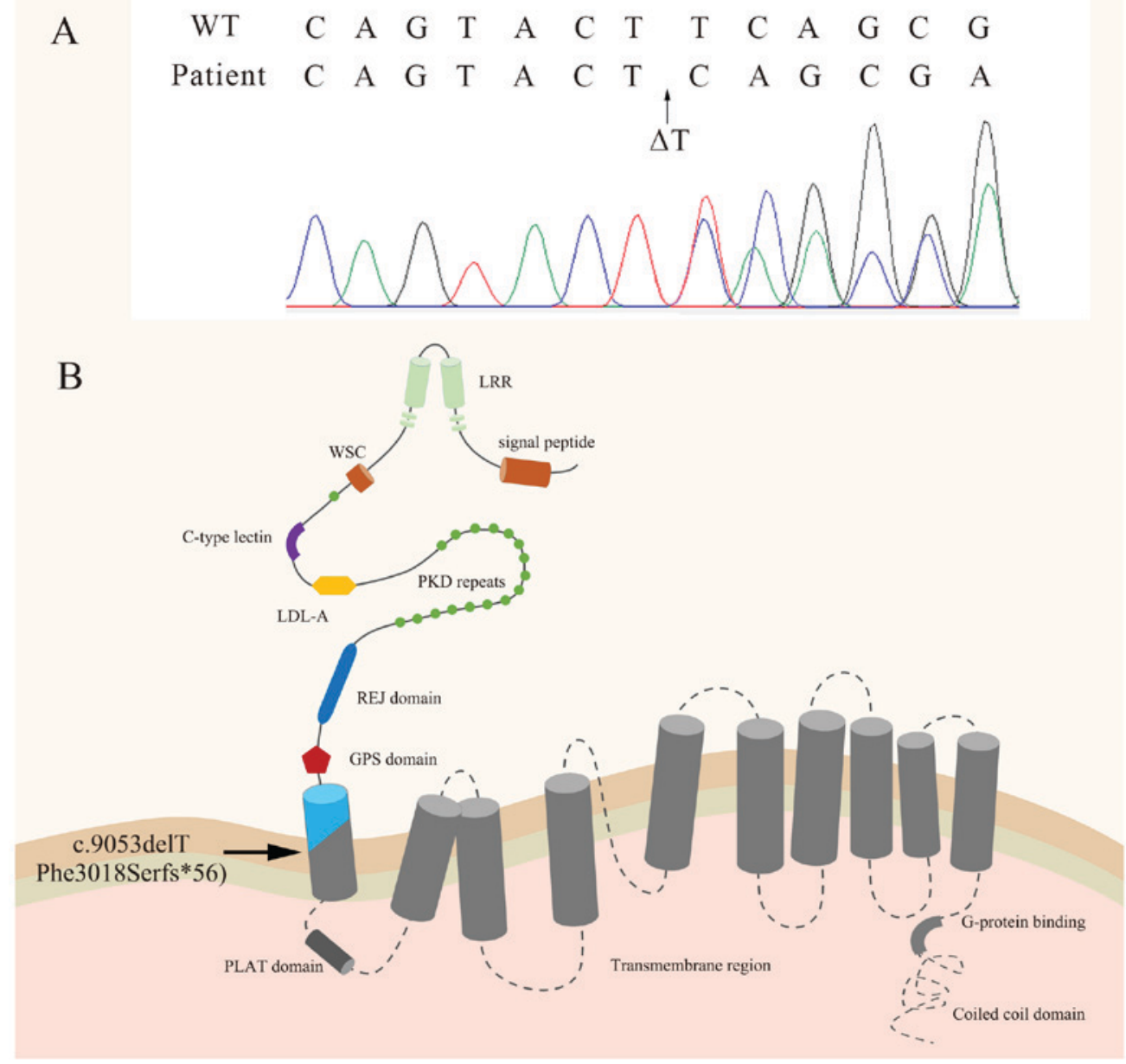

Figure 2. DNA sequencing revealing the c.9053delT mutation and aberrant PC-1 structure. (A) Direct sequence analysis of exon 25 identified c.9053delT in a heterozygous state. (B) The structure of the pathogenic PC-1 of the 33-year-old patient. WT, wild-type; PC, polycystin; LRR, leucine-rich repeats; WSC, wall stress-responsive component domain; LDL-A, low-density lipoprotein-A; REJ, receptor for the egg jelly; GPS, G protein-coupled receptor proteolytic site; PLAT domain, polycystin-1, lipoxygenase and $\alpha$-toxin; PKD1, polycystin 1, transient receptor potential channel interacting.

are not able to precisely recognize complex regions, including segmental duplications, extreme GC content and gaps $(21,22)$. The PKD1 gene is $\sim 50 \mathrm{~kb}$ long, contains 46 exons and encodes an open reading frame of $12,909 \mathrm{bp}$, whereas the PKD2 gene is $\sim 68 \mathrm{~kb}$ long, contains 15 exons and encodes an open reading frame of 2,904 bp. The sequencing of PKD1 is complex due to the six duplicated pseudogenes adjacent to it, which are highly homologous with exons 1-33 of PKD1 (23). Due to the long range and the six pseudogenes, single-molecule long-read sequencing is more suitable for the detection of genetic variants in patients with ADPKD (24-26). In the present study, long-range PCR (LR-PCR) amplification and targeted next-generation sequencing, as described previously (27), was used to detect the variants of PKD1 and PKD2 in the 33-year-old male patient. No PKD2 mutation was identified; however, a T-allele deletion causing a frameshift mutation was identified at the 9,053th position of PKD1 complementary DNA. Subsequent to comparing this alteration with the wild-type PKD1 gene, it was identified that this frameshift mutation not only causes the 3,018th amino acid of PC-1 to change from phenylalanine to serine, but also leads to an early termination of protein translation. PC-1 is a membrane protein composed of an $\mathrm{N}$-terminal extracellular portion, 11 transmembrane (TM) domains and a short intracellular C-terminal tail, which is able to directly bind PC-2 and
G proteins to initiate multiple signaling pathways (28-31). The c.9053delT is a frameshift mutation, which leads to the formation of a stop codon downstream of c.9053delT. This truncated polypeptide consists of 3,017 intact and 56 unique amino acids, without the TM region or the intracellular C-terminal tail. Therefore, the c.9053delT mutation may be disease-causing.

For patients with ADPKD, the predominant manifestation is numerous enlarged cysts in the bilateral kidneys. However, the disease severity and renal survival times are different between patients with mutant PKD1 and PKD2: Patients with PKD1 mutations frequently have a shorter renal survival time and suffer from end-stage renal disease (ESRD) 20 years earlier compared with patients with mutant PKD2 $(32,33)$. The greater disease severity associated with the PKD1 mutations is caused by the earlier onset of cyst formation, not the faster cyst growth (34). The additional renal manifestations vary among patients; furthermore, cyst formation in the liver is the most common sign associated with the disease, detected in $\sim 83 \%$ of patients with ADPKD (35). Intracranial aneurysms are additionally associated with the disease, with a prevalence of 9-12\%, and raise the risk of cerebrovascular accident (36). In the present study, the 33-year-old patient sought medical advice for abdominal pain and azoospermia. Chronic abdominal pain is a common complaint, and a study from the HALT-PKD Trial 
documented complaints of abdominal fullness and pain which were severe in patients with advanced disease, possibly due to organ enlargement (37). The total kidney volume (TKV) was identified as a critical biomarker to predict the progression of ADPKD in recent studies; according to a clinical evaluation model, an eGFR of $<50 \mathrm{ml} / \mathrm{min} / 1.73 \mathrm{~m}^{2}$ and a TKV of the bilateral kidneys of $>1,000 \mathrm{~cm}^{3}$ is associated with an estimated median disease course of ESRD of 4 years (38-40). Therefore, the 33-year-old patient was advised to maintain good renal function to prolong the renal survival time, by having a low sodium diet, drinking more water and avoiding strenuous exercise. In patients with ADPKD, seminal vesicle cysts represent a common additional renal manifestation with a prevalence of $39-60 \%$, as opposed to a prevalence of $5 \%$ in the general population; however, these cysts are rarely associated with infertility in male patients with ADPKD $(41,42)$. A number of previous case reports regarding infertility and azoospermia in patients with ADPKD have been published, which suggest that the lack of PC-1 or PC-2 may result in the obstruction or atonicity of seminal vesicles or ejaculatory duct cysts and lead to ejaculation failure (43-47). In the present study, the ultrasound examination detected the presence of epididymis cysts and dilated seminal vesicles; however, the testicular biopsy identified mature sperm. This suggested that the cysts of the epididymis and the dilated seminal vesicles may obstruct the ejaculation of semen. May result in the obstruction or atonicity of seminal vesicles or ejaculatory duct cysts and lead to ejaculation failure

In summary, the patient presented in this case study suffered from ADPKD and azoospermia due to a novel mutation in the PKD1 gene, c.9053delT. Assisted reproductive technology coupled with pre-implantation genetic diagnosis of ADPKD may be used to eliminate the inheritance of this mutation to produce a healthy embryo $(48,49)$.

\section{Acknowledgements}

The authors would like to thank Dongyue Ma, Qingsong Niu and Zhengming Bai, Anhui Province PKD Center, The First Affiliated Hospital of Anhui Medical University, (Hefei, China), for their help in recording the medical history of the patient.

\section{Funding}

The present study was supported by a grant from the Sci-Tech Planning Projects of Anhui Province, China (grant no. 1704e1002230 to CL).

\section{Availability of data and materials}

The datasets generated and/or analyzed during the current study are available from the corresponding author on reasonable request.

\section{Authors' contributions}

CZL performed the clinical examination and diagnosed the patient with ADPKD, as well as reviewed the manuscript. JLM recorded and analyzed the results from the clinical examinations.
JLM and SXF obtained the blood samples, extracted the total DNA, completed the long-range PCR (LR-PCR) amplification and the targeted next-generation sequencing. JLM and YCX recorded and analyzed the results from the clinical examinations. All authors read and approved the final manuscript.

\section{Ethics approval and consent to participate}

Informed consent for participation in the study was obtained.

\section{Patient consent for publication}

The patient provided written informed consent regarding the publication of his data and images.

\section{Competing interests}

The authors declare that they have no competing interests.

\section{References}

1. Dalgaard OZ: Bilateral polycystic disease of the kidneys; a follow-up of two hundred and eighty-four patients and their families. Acta Med Scand Suppl 328: 1-255, 1957.

2. Wilson PD: Polycystic kidney disease. N Engl J Med 350: 151-164, 2004

3. Willey CJ, Blais JD, Hall AK, Krasa HB, Makin AJ and Czerwiec FS: Prevalence of autosomal dominant polycystic kidney disease in the European Union. Nephrol Dial Transplant 32: 1356-1363, 2017.

4. Xue C, Zhou CC, Wu M and Mei CL: The clinical manifestation and management of autosomal dominant polycystic kidney disease in China. Kidney Dis (Basel) 2: 111-119, 2016.

5. Pei Y and Watnick T: Diagnosis and screening of autosomal dominant polycystic kidney disease. Adv Chronic Kidney Dis 17: 140-152, 2010.

6. Cornecle GE, Audrézet MP, Renaudineau E, Hourmant M, Charasse C, Michez E, Frouget T, Vigneau C, Dantal J, Siohan P, et al: PKD2-related autosomal dominant polycystic kidney disease: Prevalence, clinical presentation, mutation spectrum, and prognosis. Am J Kidney Dis 70: 476-485, 2017.

7. Reig B, Blumenfeld J, Donahue S and Prince MR: Seminal megavesicle in autosomal dominant polycystic kidney disease. Clin Imaging 39: 289-292, 2015.

8. Vikrant S and Parashar A: Autosomal dominant polycystic kidney disease: Study of clinical characteristics in an Indian population. Saudi J Kidney Dis Transpl 28: 115-124, 2017.

9. Yoshida H, Higashihara E, Maruyama K, Nutahara K, Nitatori T, Miyazaki I and Shiokawa Y: Relationship between intracranial aneurysms and the severity of autosomal dominant polycystic kidney disease. Acta Neurochir (Wien) 159: 2325-2330, 2017.

10. Zhang W, Han Q, Liu Z, Zhou W, Cao Q and Zhou W: Whole exome sequencing reveals a stop-gain mutation of PKD2 in an autosomal dominant polycystic kidney disease family complicated with aortic dissection. BMC Med Genet 19: 19, 2018.

11. Pei Y, Obaji J, Dupuis A, Paterson AD, Magistroni R, Dicks E, Parfrey P, Cramer B, Coto E, Torra R, et al: Unified criteria for ultrasonographic diagnosis of ADPKD. J Am Soc Nephrol 20: 205-212, 2009.

12. Huskisson EC: Measurement of pain. Lancet 2: 1127-1131, 1974.

13. Lek M, Karczewski KJ, Minikel EV, Samocha KE, Banks E, Fennell T, O'Donnell-Luria AH, Ware JS, Hill AJ, Cummings BB, et al: Analysis of protein-coding genetic variation in 60,706 humans. Nature 536: 285-291, 2016.

14. Gout AM, Martin NC, Brown AF and Ravine D: PKDB: Polycystic kidney disease mutation database-a gene variant database for autosomal dominant polycystic kidney disease. Hum Mutat 28: 654-659, 2007.

15. Moller M, Jöud M, Storry JR and Olsson ML: Erythrogene: A database for in-depth analysis of the extensive variation in 36 blood group systems in the 1,000 genomes project. Blood Adv 1: 240-249, 2016. 
16. Porath B, Gainullin VG, Cornec-Le GE, Dillinger EK, Heyer CM Hopp K, Edwards ME, Madsen CD, Mauritz SR, Banks CJ, et al: Mutations in GANAB, encoding the glucosidase II $\alpha$ subunit, cause autosomal-dominant polycystic kidney and liver disease. Am J Hum Genet 98: 1193-1207, 2016.

17. Codinasolà M, Rodríguezsantiago B, Homs A, Santoyo J, Rigau M, Aznar-Laín G, Del Campo M, Gener B, Gabau E, Botella MP, et al: Integrated analysis of whole-exome sequencing and transcriptome profiling in males with autism spectrum disorders. Mol Autism 6: 21, 2015.

18. Oliver GR, Hart SN and Klee EW: Bioinformatics for clinical next generation sequencing. Clin Chem 61: 124-135, 2015.

19. Edrees BM, Athar M, Al-Allaf FA, Taher MM, Khan W, Bouazzaoui A, Al-Harbi N, Safar R, Al-Edressi H, Alansary $\mathrm{K}$, et al: Next-generation sequencing for molecular diagnosis of autosomal recessive polycystic kidney disease. Gene 591: 214-226, 2016.

20. Ranjzad F, Aghdami N, Tara A, Mohseni M, Moghadasali R and Basiri A: Identification of three novel frameshift mutations in the PKD1 gene in iranian families with autosomal dominant polycystic kidney disease using efficient targeted next-generation sequencing. Kidney Blood Press Res 43: 471-478, 2018.

21. Steinberg KM, Schneider VA, Graves-Lindsay TA, Fulton RS, Agarwala R, Huddleston J, Shiryev SA, Morgulis A, Surti U, Warren WC, et al: Single haplotype assembly of the human genome from a hydatidiform mole. Genome Res 24: 2066-2076, 2014.

22. Chaisson MJ, Huddleston J, Dennis MY, Sudmant PH Malig M, Hormozdiari F, Antonacci F, Surti U, Sandstrom R, Boitano M, et al: Resolving the complexity of the human genome using single-molecule sequencing. Nature 517: 608-611, 2015.

23. Bogdanova N, Markoff A, Gerke V, McCluskey M, Horst J and Dworniczak B: Homologues to the first gene for autosomal dominant polycystic kidney disease are pseudogenes. Genomics 74 333-341, 2001.

24. Eisenberger T, Decker C, Hiersche M, Hamann RC, Decker E, Neuber S, Frank V, Bolz HJ, Fehrenbach H, Pape L, et al: An efficient and comprehensive strategy for genetic diagnostics of polycystic kidney disease. PLoS One 10: e0116680, 2015.

25. Carrera P, Calzavara S, Magistroni R, den Dunnen JT, Rigo F, Stenirri S, Testa F, Messa P, Cerutti R, Scolari F, et al: Deciphering variability of PKD1 and PKD2 in an italian cohort of 643 patients with autosomal dominant polycystic kidney disease (ADPKD). Sci Rep 6: 30850, 2016.

26. Borràs DM, Vossen RHAM, Liem M, Buermans HPJ, Dauwerse H, van Heusden D, Gansevoort RT, den Dunnen JT, Janssen B, Peters DJM, et al: Detecting PKD1 variants in polycystic kidney disease patients by single-molecule long-read sequencing. Hum Mutat 38: 870-879, 2017.

27. Xu D, Ma Y, Gu X, Bian R, Lu Y, Xing X and Mei C: Novel mutations in the PKD1 and PKD2 genes of Chinese patients with autosomal dominant polycystic kidney disease. Kidney Blood Press Res 43: 297-309, 2018

28. Qian F, Germino FJ, Cai Y, Zhang X, Somlo S and Germino GG: PKD1 interacts with PKD2 through a probable coiled-coil domain. Nat Genet 16: 179-183, 1997.

29. Delmas P, Nomura H, Li X, Lakkis M, Luo Y, Segal Y, Fernández-Fernández JM, Harris P, Frischauf AM, Brown DA and Zhou J: Constitutive activation of G-proteins by polycystin-1 is antagonized by polycystin-2. J Biol Chem 277: 11276-11283, 2002.

30. Dere R, Wilson PD, Sandford RN and Walker CL: Carboxy terminal tail of polycystin-1 regulates localization of TSC2 to repress mTOR. PLoS One 5: e9239, 2010.

31. Kim H, Kang AY, Ko AR, Park HC, So I, Park JH, Cheong HI, Hwang $\mathrm{YH}$ and Ahn C: Calpain-mediated proteolysis of polycystin-1 C-terminus induces JAK2 and ERK signal alterations. Exp Cell Res 320: 62-68, 2014.

32. Cornec-Le Gall E, Audrezet MP, Chen JM, Hourmant M, Morin MP, Perrichot R, Charasse C, Whebe B, Renaudineau E, Jousset $\mathrm{P}$, et al: Type of PKD1 mutation influences renal outcome in ADPKD. J Am Soc Nephrol 24: 1006-1013, 2013.

33. Kurashige M, Hanaoka K, Imamura M, Udagawa T, Kawaguchi Y, Hasegawa T, Hosoya T, Yokoo T and Maeda S: A comprehensive search for mutations in the PKD1 and PKD2 in Japanese subjects with autosomal dominant polycystic kidney disease. Clin Genet 87: 266-272, 2015.
34. Chapman AB, Devuyst O, Eckardt KU, Gansevoort RT, Harris T, Horie S, Kasiske BL, Odland D, Pei Y, Perrone RD, et al: Autosomal-dominant polycystic kidney disease (ADPKD): Executive summary from a kidney disease: Improving global outcomes (KDIGO) controversies conference. Kidney Int 88: 17-27, 2015.

35. Bae KT, Zhu F, Chapman AB, Torres VE, Grantham JJ, Guay-Woodford LM, Baumgarten DA, King BF Jr, Wetzel LH, Kenney PJ, et al: Magnetic resonance imaging evaluation of hepatic cysts in early autosomal-dominant polycystic kidney disease: The consortium for radiologic imaging studies of polycystic kidney disease cohort. Clin J Am Soc Nephrol 1: 64-69, 2006.

36. Vlak MH, Algra A, Brandenburg R and Rinkel GJ: Prevalence of unruptured intracranial aneurysms, with emphasis on sex, age, comorbidity, country, and time period: A systematic review and meta-analysis. Lancet Neurol 10: 626-636, 2011.

37. Miskulin DC,Abebe KZ, Chapman AB, Perrone RD, Steinman TI, Torres VE, Bae KT, Braun W, Winklhofer FT, Hogan MC, et al: Health-related quality of life in patients with autosomal dominant polycystic kidney disease and CKD stages 1-4: A cross-sectional study. Am J Kidney Dis 63: 214-226, 2014.

38. Perrone RD, Mouksassi MS, Romero K, Czerwiec FS Chapman AB, Gitomer BY, Torres VE, Miskulin DC, Broadbent S and Marier JF: Total kidney volume is a prognostic biomarker of renal function decline and progression to end-stage renal disease in patients with autosomal dominant polycystic kidney disease. Kidney Int Rep 2: 442-450, 2017.

39. Yu ASL, Shen C, Landsittel DP, Harris PC, Torres VE, Mrug M, Bae KT, Grantham JJ, Rahbari-Oskoui FF, Flessner MF, et al: Baseline total kidney volume and the rate of kidney growth are associated with chronic kidney disease progression in autosomal dominant polycystic kidney disease. Kidney Int 93: 691-699, 2018.

40. Xue C, Zhou C and Mei C: Total kidney volume: The most valuable predictor of autosomal dominant polycystic kidney disease progression. Kidney Int 93: 540-542, 2018.

41. Torra R, Sarquella J, Calabia J, Martí J, Ars E, Fernández-Llama P and Ballarin J: Prevalence of cysts in seminal tract and abnormal semen parameters in patients with autosomal dominant polycystic kidney disease. Clin J Am Soc Nephrol 3: 790-793, 2008.

42. Vora N, Perrone R and Bianchi DW: Reproductive issues for adults with autosomal dominant polycystic kidney disease. Am J Kidney Dis 51: 307-318, 2008.

43. Kanagarajah P, Ayyathurai R and Lynne CM: Male infertility and adult polycystic kidney disease-revisited: Case report and current literature review. Andrologia 44: 838-841, 2012.

44. Grenha V, Pereira BJ, Retroz E, Coelhoa H Godinhoa R Temidoa P and Motaa A: Mechanisms of male infertility in autosomal dominant polycystic kidney disease. Acta Urológica Portuguesa 31: 41-44, 2014.

45. Shefi S, Levron J, Nadu A and Raviv G: Male infertility associated with adult dominant polycystic kidney disease: A case series. Arch Gynecol Obstet 280: 457-460, 2009.

46. Manno M, Marchesan E, Tomei F, Cicutto D, Maruzzi D, Maieron A and Turco A: Polycystic kidney disease and infertility: Case report and literature review. Arch Ital Urol Androl 77: 25-28, 2005.

47. Hendry WF, Rickards D, Pryor JP and Baker LR: Seminal megavesicles with adult polycystic kidney disease. Hum Reprod 13: 1567-1569, 1998

48. Li W, Ma Y, Yu S, Sun N, Wang L, Chen D, Yang G, Lu S, Li Y, Yang B and Mei C: The mutation-free embryo for in vitro fertilization selected by MALBAC-PGD resulted in a healthy live birth from a family carrying PKD 1 mutation. J Assist Reprod Genet 34: 1653-1658, 2017.

49. Murphy EL, Droher ML, Dimaio MS and Dahl NK: Preimplantation genetic diagnosis counseling in autosomal dominant polycystic kidney disease. Am J Kidney Dis: Mar 30, 2018 (Epub ahead of print). 